\title{
УДК 551.465
}

\section{ГИДРОФИЗИЧЕСКИЕ АНОМАЛИИ И ИХ СВЯЗЬ С МЕТЕОРОЛОГИЧЕСКИМ РЕЖИМОМ В РАЙОНЕ АНТАРКТИЧЕСКОЙ СТАНЦИИ АКАДЕМИК ВЕРНАДСКИЙ В ТЕЧЕНИЕ ЛЕТНИХ СЕЗОНОВ 2000-2001 гГ.}

\author{
Ю.И. Попов ${ }^{1}$, В.В. Скрыпник ${ }^{1}$, В.Е. Тимофеев ${ }^{2}$, В.В. Украинский ${ }^{1}$ \\ ${ }^{1}$ Украинский научный центр экологии моря. E-mail:ypopov@te.net.ua \\ ${ }^{2}$ Одесский Государственный Экологический университет, Львовская 15, Одесса, 65016 \\ E-mail: meteo@,ogmi.farlep.odessa.ua
}

Реферат. Дан анализ материалов впервые проведенного годового цикла наблюдений на морской акватории островов Аргентинского архипелага, где расположена украинская антарктическая станция. Рассмотрено несколько случаев значительных отклонений состояния морской среды от средних условий региона. Описаны возможные причины появления аномальных явлений.

Гідрофізичні аномалії та їх зв'язок з метеорологічним режимом у районі антарктичної станції Академік Вернадський протягом літніх сезонів 2000-2001 pp. В.Є. Тимофеєв

Проаналізовано матеріали вперше проведеного річного циклу спостережень на морській акваторії островів Аргентинського архіпелагу, де розташована українська антарктична станція. Розглянуто декілька випадків значних відхилень стану морського середовища від середніх умов регіону. Описані можливі причини появи аномальних явищ.

Hydrophysics anomalies and meteorological conditions at Akademik Vernadsky in summer seasons 2000 and 2001 by Yu.I, Popov, V.V. Skrypnik, V.Ye. Timofeyev, V.V. Ukrainsky

Abstract. For the first time the analysis of the annual cycle of the sea water conditions near the islands of Argentina archipelago, where the Ukrainian Antarctic station is located, was carried out. Some significant deviations of the marine environment state from average conditions in the region are considered.

Key words: anomaly, temperature, air pressure, sea-water, Argentina archipelago

\section{1. Введение}

Практически каждый год на антарктической станции Академик Вернадский наблюдаются существенные отклонения каких-либо измеряемых величин или природных явлений от средних значений или условий. Это могут быть отклонения температуры воздуха или морской воды, скорости ветра, атмосферного давления, осадков, общего содержания озона, ледовых условий и т.д. Причины многих аномалий известны и даже предсказуемы, и обычно они проявляются комплексом метеорологических величин и явлений. Под аномалией мы будем понимать значение измеряемой величины, близкое к ее абсолютному экстремуму за время наблюдений или превышающее его. Это может быть и метеорологический параметр, полученный при стандартных измерениях на станции, а также синоптический процесс, вызывающий несвойственные времени наблюдений (аномальные) погодные условия. Период наблюдений с 1999 по 2001 гг. охарактеризовался несколькими подобными событиями. Летом 1999/2000 г. (декабрь-январь) зарегистрирована отрицательная аномалия температуры морской воды (Timofeev, Gordijenko, 2001). Год спустя она сменилась положительной летней аномалией температуры морской воды, и отмечался необычно бурный рост диатомовых водорослей. В ноябре-декабре 2000 г. впервые отмечено формирование придонного ледового покрытия.

\section{2. Цель исследования и использованные данные}

Целью исследования является выяснение причин измеренных или замеченных аномалий на морской акватории Аргентинских островов, где расположена станция Академик 
Вернадский, в связи с изменениями метеорологической обстановки и циркуляционных условий. Использовались данные стандартных метеорологических наблюдений на станции, данные гидрологических измерений в поверхностном слое воды на береговом посту станции и на сериях океанографической якорной станции, выполнявшихся в одной точке межостровной зоны архипелага. Пробы воды на станции отбирались с четырех горизонтов - 0, 10, 20, 30 м. Для отбора проб использовались батометры БМ-48, оснащенные термометрами глубоководными “ТГ”. Электропроводность проб воды измерялась на электросолемере “ГМ65" и далее пересчитывалась в соленость. Скорость течений измерялась морской вертушкой BMM на горизонтах 0 и 30 м. Координаты океанографической станции 6514'5" ю.ш. и $64^{\circ} 17^{\prime}$ з.д. Прозрачность воды определялась визуально по кругу Секки. Координаты выхода в место выполнения океанографической станции фиксировались портативной GPS “Garmin-12” с дополнительным использованием естественных ориентиров на островах Три маленьких поросенка и Барханс.

Были использованы также синоптические приземные карты Чилийской военной службы, принимавшиеся на станции Академик Вернадский на протяжении 2000 г. Использовались и данные полевых исследований (наблюдения за морским льдом и гидрология), проведенные в сезонах 1999/2000 и 2000/2001 гг.

\section{3. Результаты работы}

Как отмечалось выше, в январе-марте 2000 г. наблюдались отрицательные аномалии температуры морской воды. Температура воды оставалась ниже $0^{\circ} \mathrm{C}$ вплоть до 13 января 2000 г., тогда как обычно переход через 0 отмечается во второй половине декабря предшествующего года. Устойчивый период положительных температур отмечался в период 16.01.-19.03.2000 г. Максимальные положительные температуры в теплое время года не превышали $0,6^{\circ} \mathrm{C}$. Основной причиной этой аномалии было сохранение большого количества морского льда вплоть до начала лета 1999-2000 гг.

Аномалия обратного знака стала проявляться в конце ноября 2000 г. Устойчивый переход температуры поверхностного слоя вод через 0 отмечен с 03.12.2000 г. (рис. 1). В последний день декабря температура воды по данным прибрежных наблюдений достигла $+3,7^{\circ} \mathrm{C}$, а во время полевых работ на морской акватории $+4,9^{\circ} \mathrm{C}$. По данным рейдовой океанографической станции в период с начала февраля по конец 1-ой декады марта 2001 г.

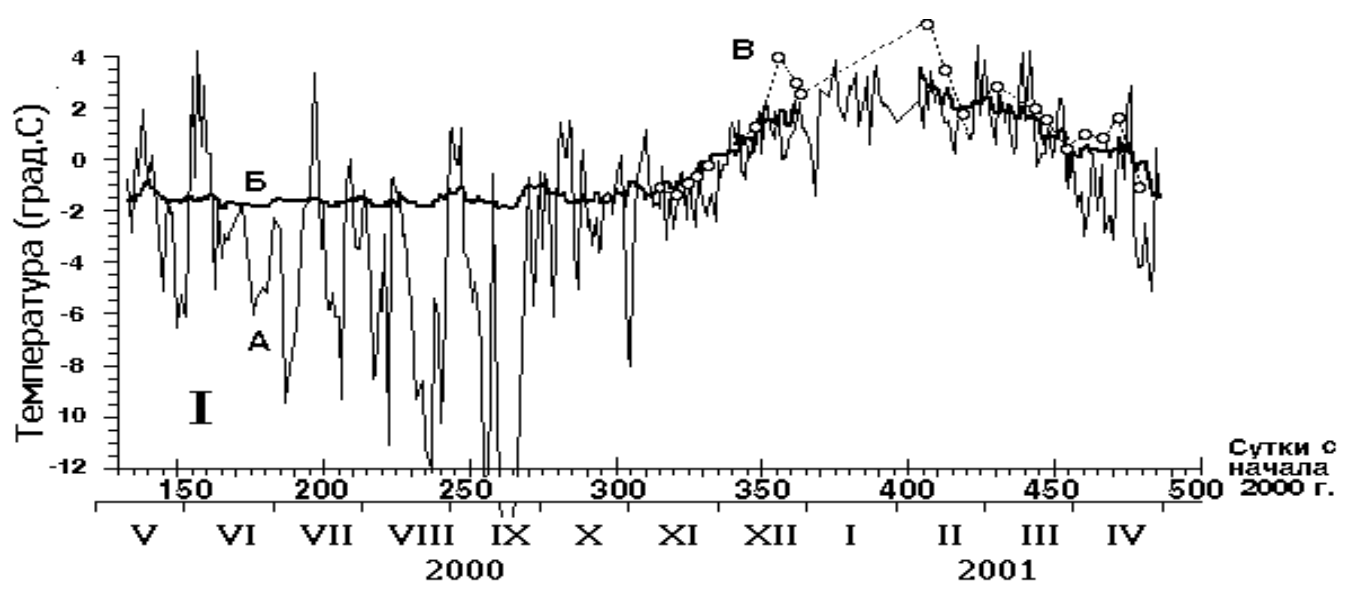

Рис.1. Годовой цикл изменений А) температуры воздуха, Б) прибрежной температуры воды и В) температуры воды поверхностного слоя по данным океанографических серий на антарктической станции Академик Вернадский (12.05.2000-30.04.2001 гг.). 
температура воды на горизонте 30 м (в 5-ти метрах от дна) превышала $+2^{\circ} \mathrm{C}$. Такие высокие значения температуры воды как на поверхности, так и у дна отмечены впервые за весь период работ украинских антарктических экспедиций.

Одновременно с этим, поверхностный слой воды потерял свою прозрачность. Начиная с последней недели ноября, в районе станционного мареографа и в проливе Мик она снизилась до 2-3 м, тогда как при обычных условиях прозрачность достигает величин 20-30 м.

Кроме этого, поверхность воды приобрела темно-зеленый цвет и характерный запах водорослей ("цветение моря"). При погоде, близкой к штилевой, были видны большие колонии диатомовых водорослей как на акватории перед станцией, так и в открытом море. Такая же ситуация отмечалась во время двух полевых выходов на расстоянии 40-50 км к северу от станции, вплоть до Порт-Локроя. Первый выход к американской станции Палмер был предпринят 10 декабря. Прозрачность поверхностных вод составила 5 м в заливе АртурХарбор и немногим более 10 м в проливе Бисмарк. Во время второй поездки (21 декабря 2000 г.) цветение морской воды было также значительным. Прозрачность морской воды по всему маршруту полевых работ (в том числе в проливе Жерлаш и в заливе Парадайс-Бей) и вблизи о. Галиндез была менее 3 метров. К сожалению, авторы не располагают данными наблюдений в проливе Брансфилд и на акваториях вблизи о. Кинг-Джордж. Поэтому определить полный пространственный масштаб явления пока не представляется возможным. В. Скрыпнику, посетившему польскую станцию Арктовски в 2001 году, не удалось получить информацию о развитии аналогичных процессов в районе о. Кинг-Джордж.

Годовой ход солености поверхностного слоя морской воды имеет максимум зимой (в августе-сентябре) при ледообразовании и минимум летом (декабрь, январь, рис. 2), когда происходит интенсивное таяние льдов. Февраль 2001 года характеризовался мощным положительным отклонением солености (до 1 епс) от крупномасштабной сезонной волны изменчивости. Температуры воздуха и моря в этот период были еще достаточно высокими, и можно было бы предполагать продолжения процесса распреснения морских вод. Поскольку существенных изменений атмосферной циркуляции и ледовой обстановки не отмечалось, то причиной спорадического осолонения вод могло быть изменение направленности крупномасштабной морской циркуляции и адвективное поступление высокосоленых вод.

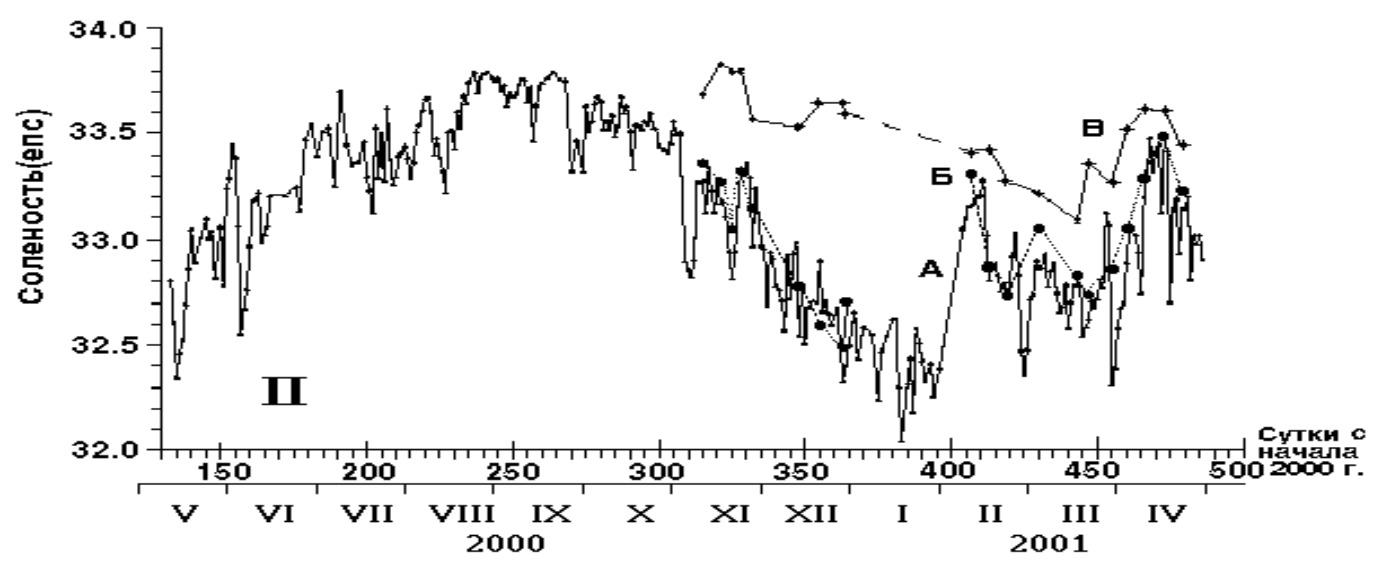

Рис. 2. Годовой цикл изменений А) прибрежной солености воды, Б) солености воды поверхностного слоя и В) солености воды на горизонте 30 м по данным океанографических серий на антарктической станции Академик Вернадский (12.05.2000-30.04.2001 гг.).

Очевидно, в связи с термической аномалией на морской акватории в районе архипелага Аргентинские острова практически полностью исчез криль и значительно сократилась численность китов, морских котиков и тюленей Уэдделла. 
Анализ метеорологических условий и синоптической ситуации показывает, что аномалии развивались на фоне слабого ветра и слабовыраженных течений в поверхностном слое океана. Метеорологические условия в декабре 2000 г., когда положительная аномалия температуры воды достигла максимума, представлены в таблице.

Таблица. Средние и экстремальные данные метеорологических величин в декабре 2000 г., антарктическая станция Академик Вернадский.

\begin{tabular}{|c|c|c|c|c|c|c|c|c|}
\hline $\begin{array}{c}\text { Даты, } \\
2000 \\
200 \text { рь }\end{array}$ & $\begin{array}{c}\text { Атмосфер- } \\
\text { ное давление, } \\
\text { гПа }\end{array}$ & $\begin{array}{c}\text { Скорость } \\
\text { ветра, } \\
\text { узлы }\end{array}$ & $\begin{array}{c}\text { Сумма } \\
\text { штилей, } \\
\text { часы }\end{array}$ & $\begin{array}{c}\text { Средняя } \\
\text { температу- } \\
\text { ра воздуха, } \\
\left({ }^{\circ} \mathbf{C}\right)\end{array}$ & $\begin{array}{c}\mathrm{T}_{\text {макс. }} \\
\left({ }^{\circ} \mathrm{C}\right)\end{array}$ & $\begin{array}{c}\mathrm{T}_{\text {мин. }} \\
\left({ }^{\circ} \mathrm{C}\right)\end{array}$ & $\begin{array}{c}\text { Влажность } \\
(\%)\end{array}$ & $\begin{array}{c}\text { Сумма } \\
\text { часов сол- } \\
\text { нечного } \\
\text { сияния }\end{array}$ \\
\hline $1-10$ & 988.0 & 5.6 & 8.0 & 0.25 & 4.8 & -2.0 & 82 & 45.7 \\
\hline $10-20$ & 993.2 & 6.6 & 3.2 & 1.2 & 4.8 & -1.0 & 80 & 57.7 \\
\hline $20-25$ & 987.2 & 7.3 & 0.7 & 0.45 & 4.2 & -1.5 & 82 & 38.9 \\
\hline $26-31$ & 983.3 & 5.3 & 1.3 & 2.6 & 7.1 & 0.1 & 72 & 67.1 \\
\hline
\end{tabular}

Атмосферное давление в декабре 2000 г. колебалось незначительно, в основном, в границах диапазона 980-1003 гПа (среднесуточные величины), что явилось отражением слабой циклонической активности атмосферы в этом месяце и причиной преобладания слабых ветров (менее 4 м/с), доля которых составила 73\%.

Максимального значения температура воды достигла в последний день года. В этот же период отмечена и максимальная температура воздуха $+7.1^{\circ} \mathrm{C}$. В целом, в течение последних 6 дней 2000 года отрицательные температуры воздуха не регистрировались, преимущественно из-за ясной погоды (за эти 6 дней сумма солнечного сияния составила 67.1 час.) при максимальной высоте Солнца.

Другой возможной причиной мощной вспышки диатомовых водорослей могли быть ледовые условия. Они характеризовалось наличием как обычного плавучего льда (битый лед, остатки айсбергов), так и донного льда. Еще в сентябре отмечалось наличие льдин темнокоричневого цвета. Возможно, что при последующем таянии льда определенный запас диатомовых водорослей, привнесенных плавучим льдом, длительное время оставался в поверхностном слое воды, чему благоприятствовали слабые ветровые условия и, при аномальном повышении температуры воды, явился источником для бурного развития фитопланктона.

Донный лед наблюдался в сентябре-октябре вдоль береговых склонов проливов Стелла и Мик до значительных глубин (10-15 м).

В период с 14.09 по 30.09 отмечалось самое мощное и одно из последних в это лето вторжение холодного континентального воздуха. К 19-20 августа среднесуточная температура воздуха упала до $-16^{\circ} \mathrm{C}$ (годовой экстремум). В конце периода выхолаживания ветры сменили направление на традиционное северо-восточное, и за трое суток температура воды поднялась до $-1{ }^{\circ} \mathrm{C}$. Температура придонного слоя вод еще длительное время могла оставаться на прежнем низком уровне из-за теплообмена с мощным аккумулятором холода - каменным ложем дна. На завершающей стадии подъема поверхностной температуры воды на акваторию станции была привнесена вода с соленостью 33.30 епс, что на 0.5 епс ниже, чем ранее наблюдавшаяся. Распреснение вод с такой соленостью на 0.5 епс вызывает повышение температуры точки замерзания морской воды всего лишь на $0.03^{\circ} \mathrm{C}$. Но, видимо, этой величины оказалось достаточно для того, чтобы холодное каменное ложе проливов покрылось тонким слоем придонного льда. Внутриводный лед - явление не редкое в водах высоких широт (Козловский, Черепанов, 1973). Он образуется регулярно в периоды весенних потеплений за счет подтекания талых вод под ледовый покров моря. При этом создается очень прочный слой прозрачного льда, подстилающего сплошной ледяной покров. В нашем случае сплошной ледяной покров отсутствовал, и генезис придонного льда был связан исключительно с адвективным 
внедрением вод с пониженной соленостью и сохранением очень низких термических условий у границы вода-дно.

Близкие условия для донного ледообразования имели место в конце июля и во второй декаде августа, однако ледообразование зафиксировано не было.

Анализ синоптических ситуаций показал следующее. Отличительной особенностью второй половины ноября и всего декабря 2000 г. стало преобладание антициклональной погоды и малоградиентного барического поля. В ноябре антициклоны преобладали в 60\%, а в декабре в 50\% случаев. Траектории циклонов были смещены к северу или к югу от широты антарктической станции, пролегая над проливом Дрейка или Землей Палмера. Активный циклон над станцией отмечен лишь в начале декабря. В большинстве случаев антициклональное или малоградиентное поле отмечено для области моря Беллинсгаузена, лежащей на $20^{\circ}$ западнее станции Академик Вернадский. В это время через район станции обычно пролегают траектории западных циклонов. Устойчивую погоду в районе станции в декабре 2000 г. поддерживал и гребень континентального антарктического антициклона, который в дни своей активизации соединялся с одним из гребней субтропических максимумов с образованием единой области высокого давления над морем Беллинсгаузена.

\section{4. Обсуждение}

Возможным предвестником для повышения температуры моря могло стать обострение озоновой дыры в середине октября 2000 г. При увеличении потока ультрафиолетовой радиации поверхностные воды прогреваются больше и скорость фотосинтеза изменяется (Smith, 1992). Известно, что наиболее благоприятные условия для фотосинтеза создаются при интервале температур морской воды от +1 до $+4^{\circ} \mathrm{C}$, а именно такие значения отмечены по данным станции Вернадский в декабре 2000 г. При слабо развитой циркуляции поверхности океана создаются условия для накопления первичной биомассы.

Таким образом, общие условия для развития биомассы в поверхностном слое океана известны, однако для каждого отдельного региона они дополняются местными особенностями. Станция Вернадский находится вблизи Антарктического полуострова и многочисленных островов, между которыми существует зона затишья. В условиях устойчивой погоды, подобной описанной выше, а также слабой турбулентности верхнего слоя океана, формируются идеальные условия для накопления биомассы. Фактически, ее воспроизводство начинается раньше, когда тает зимний лед и образуется устойчиво стратифицированный поверхностный водный слой, препятствующий проникновению биомассы вглубь. С другой стороны, район станции Вернадский относится к краевой зоне распространения морских льдов, для которой описанные процессы характерны.

\section{5. Выводы}

Две различных аномалии температуры воды поверхности океана наблюдались в течение летних сезонов 1999-2000 и 2000-2001 гг. Основную роль в их формировании сыграли погодные условия и ледовая обстановка.

Отрицательная аномалия в декабре 1999 г. и январе 2000 г. развивалась на фоне большого количества льда, сохранившегося после зимы в районе морской акватории Аргентинских островов.

Положительная аномалия температуры поверхностного слоя воды формировалась в условиях преобладания антициклонических или малоградиентных барических полей, больших сумм солнечного сияния и незначительных атмосферных осадков. Траектории циклонов проходили к северу или к югу от станции Академик Вернадский. В результате вышеописанных погодных условий произошло быстрое прогревание верхней толщи моря до аномально высокого уровня $\left(+3 \div+5^{\circ} \mathrm{C}\right)$ и начался бурный рост фитопланктона. В условиях умеренных широт указанный диапазон температуры морской воды является наиболее благоприятным при 
весеннем развитии фитопланктона (вызывает т.н. “весенние вспышки”) (Виноградова и др., 1990).

Очевидно, что условия для аномального роста диатомовых водорослей в поверхностном слое океана формировались задолго до наступления летнего сезона 2000-2001 гг. Предшествующей зимой не было отмечено формирования прочного припайного льда и большого количества айсбергов, в связи с чем уже в ноябре ледовая обстановка была значительно более благоприятная, чем в соответствующий период 1999-2000 гг.

Очень важно подробно рассматривать условия формирования каждой из подобных аномалий и особенно тех, которые являются следствием проявления эффектов глобального потепления климата. Экологическая система района Антарктического полуострова особенно уязвима, поскольку составляющий ее основу животный мир приспособлен к достаточно узкому интервалу температур воздуха и морской воды, а неизбежное обескислораживание вод при ее мощной эвтрофикации является губительным для всех видов фауны во всех районах Мирового океана.

\section{Литература}

Timofeev V.E., Gordijenko S.I. Meteorological conditions of survival at Vernadsky Base region environment // First Ukrainian Antarctic Meeting, Ukraine, Kyiv, June 4-7, 2001.- P.96.

Козловский А.М., Черепанов Н.В.. Ледоисследовательские работы // Тр. САЭ. - Том 61. - 1973. - C. 92-138.

Smith R.C., Prezelin B.B. et al. Ozone depletion: Ultraviolet Radiation and Phytoplankton Biology in Antarctic Waters. // Science. - 1992. - V. 255. - P. 893-959.

Виноградова Л.А., Василева В.Н., Дерезюк Н.В. и др., Экологическая модель функционирования морского пелагического биоценоза // Тр. ГОИН. - Вып. 182. -М.: Гидрометеоиздат, 1990. - С. 134-164. 